\title{
Perangkat Lunak Bantu Pendaftaran Peserta Ujian (DPU) Pada Sekolah Dasar (SD) di Dinas Pendidikan dan Kebudayaan Kota Pagar Alam Berbasis Web
}

\author{
Bhebeind Aryanto Phubenast, Asminah \& Risnaini Masdalipa \\ Sekolah Tinggi Teknologi Pagar Alam \\ Email: risnainipga@gmail.com
}

\begin{abstract}
Management of Primary School (SD) Exam Participant Registration (DPU) at the Pagar Alam City Education and Culture Office is currently still done manually, namely by recording it in a ledger then the operator manages the data using Microsoft word and Microsoft Excel so it takes a long time to get good results. With the new system that can later create data processing effectively and efficiently, for this success a better system of data processing software is needed as a tool to reduce the error rate in the data search process for Primary School Exam Participant Registration (DPU). (SD). The method used in this research is the waterfall method which has the following sequence of communication, planning, modeling, construction and distribution. Based on the summary above, the authors are interested in raising the Software for Assisting Exam Participant Registration (DPU) in Elementary Schools (SD). At the Department of Education and Culture of the City of Pagar Alam.
\end{abstract}

Keywords: assistive software, exam participant registration

\section{Pendahuluan}

Kemajuan teknologi informasi sangat cepat dari tahun ke tahun hal ini merupakan bukti bahwa manusia selalu berusaha untuk mendapatkan cara yang mudah, cepat dan akurat dalam memenuhi kebutuhan informasi dalam kehidupan mereka. Teknologi informasi sangat penting karena dengan adanya teknologi informasi dapat menambah pengetahuan, mengurangi ketidakpastian dan resiko kegagalan serta dapat membantu para pemimpin dalam mengambil suatu kesimpulan dan keputusan yang efektif dan efisien.

Perkembangan teknologi hingga saat ini sangat banyak membawa manfaat dan menghasilkan kemudahan serta membantu manusia dalam menyelesaikan berbagai pekerjaan, misalnya komputer untuk melakukan pengolahan data secara sistematis, pengolahan data statistik dan lain sebagainya, sehingga komputer merupakan salah satu alat bantu yang wajib dimiliki oleh setiap instansi pendidikan. Apabila instansi pendidikan tidak dapat mengoptimalkan penggunaan komputer dalam setiap proses kerjanya, maka instansi pendidikan akan mengalami kesulitan untuk berkembang. Salah satu cara mengoptimalkan penggunaan komputer yaitu dengan menggunakan sistem informasi sebagai alat pengambilan keputusan yang sangat dibutuhkan untuk membuat rencana kerja atau pengembangan usaha.

Perkembangan zaman juga menuntut efisiensi dalam pekerjaan. Sekarang dunia teknologi informasi pun juga merambah di dunia birokrasi Indonesia, Untuk itu salah satunya adalah di Dinas Pendidikan Dan Kebudyaan Kota Pagar Alam. 
Sebuah Instansi Pendidikan dituntut akan kecepatannya dalam mengolah data sehingga sistem pengolahan data sangatlah penting.

Sistem informasi Pendaftaran Peserta Ujian (DPU) Sekolah Dasar (SD) yang berjalan pada bagian operator Dinas Pendidikan Kota Pagar Alam saat ini masih dilakukan secara manual. Walaupun sebagian sudah ada yang dilakukan secara komputerisasi tetapi masih bersifat stand alone sehingga pemakaian data secara bersamaan pada masing-masing unit tidak dapat dilakukan. Hal ini tentunya akan mengakibatkan lambatnya proses yang berjalan di bagian operator. Padahal bagian operator menangani Pendaftaran Peserta Ujian yang jumlahnya cukup banyak. Data Peserta Ujian di sini meliputi nama sekolah, nama peserta ujian, kartu peserta ujian, nomor kursi dan rekapulasi peserta ujian.

Pengelolahan Pendaftaran Peserta Ujian (DPU) Sekolah Dasar (SD) di Dinas Pendidikan Dan Kebudayaan Kota Pagar Alam saat ini masih dilakukan secara manual yaitu dengan cara pencatatan didalam buku besar kemudian Operator mengelolah data tersebut dengan menggunakan Microsoft word dan microsoft excel hingga membutuhkan waktu yang lama untuk mendapatkan hasil yang baik. Dengan adanya sistem yang baru nantinya dapat menciptakan pengolahan data secara efektif dan efisien, maka untuk keberhasilan ini diperlukan sistem yang lebih baik dari perangkat lunak pengolah data sebagai alat bantu untuk mengurangi tingkat kesalahan-kesalahan dalam proses pencarian data Pendaftaran Peserta Ujian (DPU) Sekolah Dasar (SD). Berdasarkan masalah tersebut, maka penulis akan melakukan penelitian dengan mengangkat judul "Perangkat Lunak Bantu Pendaftaran Peserta Ujian (DPU) Pada Sekolah Dasar (SD) Di Dinas Pendidikan Dan Kebudayaan Kota Pagar Alam ”.

\section{Tinjauan Literatur}

PHP adalah pemrograman interpreter yaitu proses penerjemahan baris kode sumber menjadi kode mesin yang dimengerti komputer secara langsung pada saat baris kode dijalankan. PHP disebut sebagai pemrograman Server Side Programing, hal ini dikarenakan seluruh prosesnya dijalankan oleh server. PHP adalah suatu bahasa dengan hak cipta terbuka atau yang juga dikenal dengan istilah Open Source, yaitu pengguna dapat mengembangkan kode-kode fungsi PHP sesuai dengan kebutuhannya. (Sibero, 2013).

Menurut (Rosa A.S dan M. Shalahuddin, 2013) Sistem basis data adalah system terkomputerisasi yang tujuan utamanya adalah memelihara data yang sudah diolah atau informasi dan membuat informasi tersedia saat dibutuhkan. Pada intinya basis data adalah media untuk menyimpan data agar dapat diakses dengan mudah dan cepat. Sedangkan menurut (Kadir Abdul, 2013), Basis Data (Database) dapat dibayangkan sebagai sebuah lemari arsip. Jika kita memiliki sebuah lemari arsip dan bertugas untuk mengelolahnya, maka kemungkinan besar kita akan melakukan hal-hal seperti memberi map pada kumpulan arsip yang akan disimpan, menentukan kelompok arsip, memberi penomoran dengan pola tertentu yang nilainya unik pada setiap map, lalu menempatkan arsip-arsip tersebut kedalam lemari arsip. (Antoni, Fikari \& Akbar, 2018; Antoni \& Akbar, 2019; Antoni, Herdiansyah, Akbar \& Sumitro, 2021; Antoni, Jie \& Abareshi, 2020). 
Menurut (Bunafit Nugroho 2011:23) dalam jurnal penelitian (Hendrianto, Dani Eko, 2014) Xampp merupakan paket PHP berbasis open source yang dikembangkan oleh sebuah komunitas Open Source. Dengan menggunakan Xampp kita tidak perlu lagi melakukan penginstalan program yang lain karena semua kebutuhan telah disediakan oleh Xampp. Beberapa pakar yang telah disediakan adalah Apache, MySql, Php, Filezila, dan PhpMyadmin. Sedangkan menurut (offset, c.v andi, 2016) Xampp adalah sebuah paket kumpulan software yang terdiri dari Apache, MySQL, PhpMyadmin, PHP, Perl, Fillezila dan lain-lain. Xampp berfungsi untuk memudahkan instalasi lingkungn $P H P$, di mana biasanya lingkungan pengembangan web memerlukan $P H P$, Apache, MySQL dan PhpMyAdmin serta software-software yang terkait dengan pengembangan web.dengan menggunakan Xampp, anda tidak perlu menginstal aplikasi-aplikasi tersebut satu persatu. Paket aplikasi perlu di extract dan di-instal terlebih dahulu, dengan memilih jenis Xampp sesuai dengan jenis Operating Sistem-nya. setelah sukses menginstal Xampp, anda dapat langsung mengaktifkan MySQL. Dari dua pengertian ini dapat disimpulkan bahwa $X A M P P$ merupakan suatu aplikasi yang berfungsi untuk membangun jaringan yang berdiri sendiri (localhost) dan merupakan salah satu paket instalasi Apache, PHP dan MySQL. Fungsinya adalah sebagai server yang berdiri sendiri, yang terdiri atas program Apache HTTP server. Hubungan dengan penelitian ini, peneliti menggunakan aplikasi Xampp sebagai server untuk localhost dalam pembuatan database dengan MySql.

Axure $R P$ merupakan salah satu desain yang di spesialisasi dalam perancangan aplikasi berbasis browser, 12 tahun kemudian Axure RP dikenal sebagai sebuah standar dalam pembuatan perancangan sebuah aplikasi (Setiawan, 2017). Hubungan dengan penelitian ini, peneliti membuat perancangan suatu sistem menggunakan Axure.

\begin{tabular}{|c|c|c|c|}
\hline No & Peneliti & Judul & Hasil \\
\hline 1. & $\begin{array}{l}\text { Ferry Sudarto, Novi } \\
\text { Cholisoh, } \\
\text { Savana Putri }\end{array}$ & $\begin{array}{l}\text { Sistem } \\
\text { pengambilan kartu ujian } \\
\text { mahasiswa plus berbasis } \\
\text { web }\end{array}$ & $\begin{array}{l}\text { Dengan dibuatnya } r \text { sistem } \\
\text { informasi pengambilan kartu } \\
\text { ujian mahasiswa plus (KUM+) } \\
\text { ini dapat memudahkan } \\
\text { mahasiswa dalam mengakses } \\
\text { jadwal ujian yang dapat } \\
\text { dilakukan dimana saja dan kapan } \\
\text { saja, mahasiswa tidak harus lagi } \\
\text { datang kekampus untuk } \\
\text { mengambil kartu ujian, } \\
\text { mahasiswa tidak harus lagi } \\
\text { mengantri dan mahasiswa tidak } \\
\text { harus lagi mengisi form } \\
\text { pengambilan kartu ujian }\end{array}$ \\
\hline 2. & $\begin{array}{r}\text { Susilowati, } \\
\text { Hidayat }\end{array}$ & 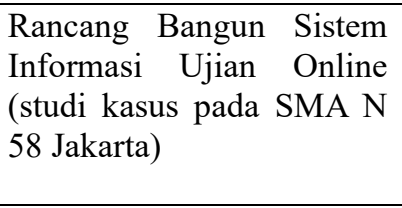 & $\begin{array}{l}\text { Dengan memakai sistem yang } \\
\text { baru dan telah } \\
\text { terkomputerisasi }\end{array}$ \\
\hline
\end{tabular}




\begin{tabular}{|c|c|c|c|}
\hline No & Peneliti & Judul & Hasil \\
\hline & & & $\begin{array}{l}\text { pelaksanaan dan } \\
\text { pengolahan data ujian. }\end{array}$ \\
\hline 3. & $\begin{array}{l}\text { Nasril, Adri } \\
\text { Saputra (2016) }\end{array}$ & $\begin{array}{l}\text { Rancang bangun system } \\
\text { inofrmasi ujian online }\end{array}$ & $\begin{array}{l}\text { Penggunaan sistem informasi } \\
\text { yang } \\
\text { sudah dikomputerisasikan } \\
\text { sangatlah } \\
\text { penting dalam pelaksanaan ujian } \\
\text { sekolah karena dapat menghemat } \\
\text { waktu dan } \\
\text { dalam pelaksanaanya } \\
\text { mengurangi } \\
\text { tingkat kecurangan siswa dalam } \\
\text { mengerjakan soal ujian. }\end{array}$ \\
\hline 4 & $\begin{array}{l}\text { M. Rafqi Tsani, } \\
\text { Nurhadianto (2015) }\end{array}$ & $\begin{array}{l}\text { Sistem informasi ujian } \\
\text { berbasis web server SMK } \\
\text { bina islam mandiri } \\
\text { (BISMA) kersana brebes } \\
\text { tegal }\end{array}$ & $\begin{array}{l}\text { Sistem ujian web server ini dapat } \\
\text { membantu guru dalam } \\
\text { memberikan nilai pada anak } \\
\text { didiknya yang } \\
\text { telah melaksanakn ujian di } \\
\text { karenakan sistem ini langsung } \\
\text { memberikan hasil berupa nilai } \\
\text { ujian setelah } \\
\text { siswa melaksanakan ujian. } \\
\text { Sistem ujian berbasis web ini } \\
\text { dapat diakses melalui jaringan } \\
\text { lokal berupa kabel LAN yang } \\
\text { terhubung } \\
\text { pada server local. }\end{array}$ \\
\hline
\end{tabular}

\section{Metode Penelitian}

Lokasi Pelaksanaan Penelitian dilakukan di Dinas Pendidikan Dan Kebudayaan, Jalan Laskar Wanita Mentarjo Komplek Perkantoran Gunung Gare Kota Pagar Alam.

Metode pengembangan yang digunakan adalah metode web engineering prosedur dari metode web engineering adalah mengerjakan secara bertahap tidak ada loncatan dari satu tahap ke tahap yang lain.

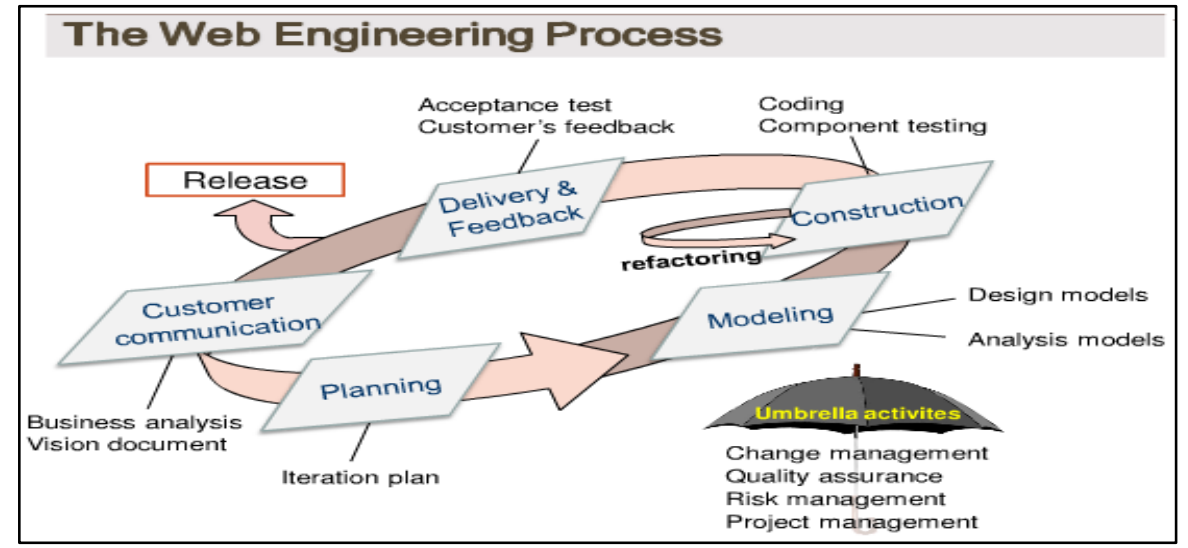

Published by: 


\section{Gambar 1 Web Engineering}

Berdasarkan penelitian yang telah di lakukan dengan melakukan observasi langsung (Fitriya, Dencik \& Asiati, 2019) di Dinas Pendidikan Dan Kebudayaan Kota Pagar Alam di dapatkan data bahwa sistem yang berjalan ketika ingin melakukan konsultasi atau melihat sistem pendaftaran peserta ujian (DPU), dan setelah tiba di Dinas Pendidikan Dan Kebudayaan Kota Pagar Alam Operator Dinas Pendidikan Dan Kebudayaan mengumpulkan daftar peserta ujian (DPU dengan menggunakan microsoft excel sehingga operator kesulitan dalam pengelolaan data siswa

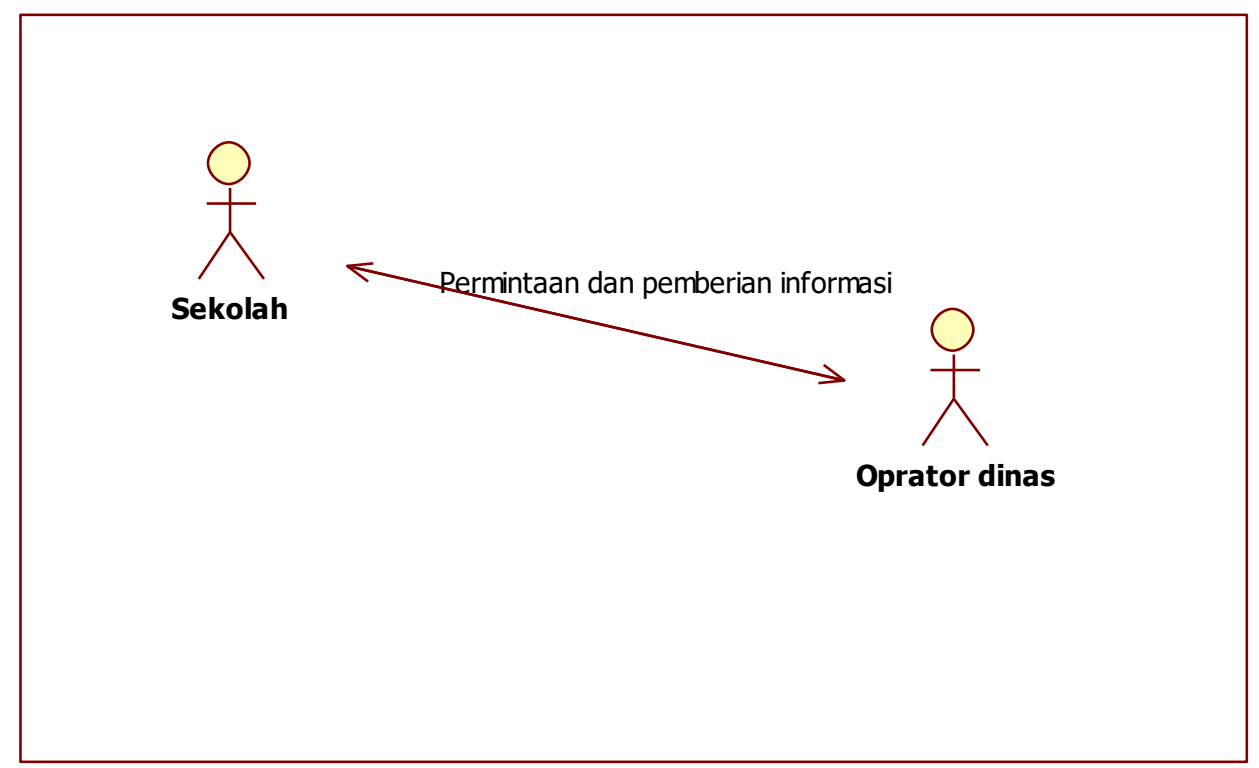

Gambar 2. Sistem yang berjalan

Sistem yang di usulkan pada perancangan ini adalah suatu sistem yang mempermudah Operator Dinas Pendidikan Dan Kebudayaan untuk mengecek pendaftaran peserta ujian (DPU) dan mempermudah proses pengelolahan Pendaftaran Peserta Ujian (DPU) di sekolah dasar (SD) Di Dinas Pendidikan Dan Kebudayaan kota Pagar Alam. Berikut gambaran dari sistem yang diusulkan untuk pengolahan Pendaftaran Peserta Ujian (DPU) Pada sekolah dasar (SD) Di Dinas Pendidikan Dan Kebudayaan: 


\begin{tabular}{r|l|lr}
$\mathrm{J}$ & $\mathrm{N}$ & $\begin{array}{l}\text { JURNAL } \\
\text { NASIONAL }\end{array}$ & Jurnal Nasional Ilmu Komputer \\
$\mathrm{I}$ & $\mathrm{K}$ & $\begin{array}{l}\text { ILMU } \\
\text { KOMPUTER }\end{array}$ & e-ISSN: 2746-1343 \\
\hline
\end{tabular}

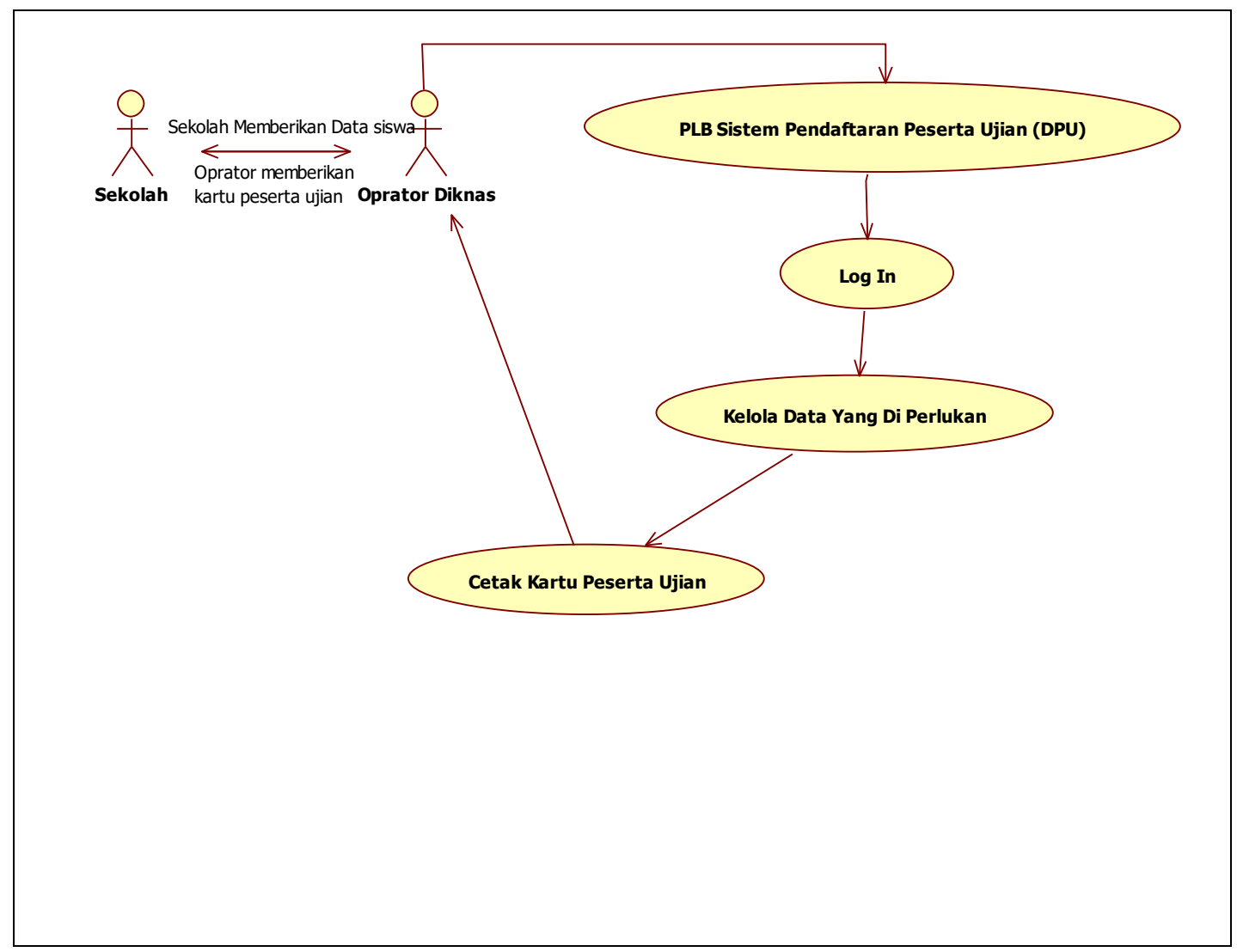

Gambar 3. Sistem yang diusulkan

\section{Hasil dan Pembahasan}

Pada bab ini peneliti akan menjelaskan tentang hasil dari penelitian yaitu Perangkat Lunak Bantu Pendaftaran Peserta Ujian (DPU) Pada Sekolah Dasar (SD) Di Dinas Pendidikan Dan Kebudayaan Kota Pagar Alam. Dengan dibangunya Perangkat Lunak Bantu Pendaftaran Peserta Ujian (DPU) Pada Sekolah Da sar (SD) Di Dinas Pendidikan Dan Kebudayaan Kota Pagar Alam ini dapat mempermudah dinas pendidikan dalam melakukan pengelolaan data siswa secara cepat, dan hemat, serta dapat dilakukan kapanpun dan dimanapun tanpa mengenal jarak dan waktu.

Pembuatan sistem ini berdasarkan dengan desain sistem yang telah dibuat pada bab sebelumnya, pengujian dalam penelitian ini dilakukan kepada dua (2) aktor berdasarkan perancangan pada bab sebelumnya yaitu Sekolah dan dinas pendidikan pengujian ini di lakukan dengan cara quesioner atau menyebarkan angket kepada user. Adapun angket yang disebarkan kepada 8 orang responden. Pengujian ini dilakukan agar mengetahui kesalahan dan kekurangan yang ada pada Perangkat Lunak Bantu Pendaftaran Peserta Ujian (DPU) Pada Sekolah Dasar (SD) Di Dinas Pendidikan Dan Kebudayaan Kota Pagar Alam 
juga untuk mengetahui tanggapan user terhadap Perangkat Lunak Bantu Pendaftaran Peserta Ujian (DPU) Pada Sekolah Dasar (SD) Di Dinas Pendidikan Dan Kebudayaan Kota Pagar Alam, serta seberapa layak sistem untuk di implementasikan.

Teknik pengolahan data yang digunakan yaitu menggunakan skala likert. Menurut Anwar dalam buku (Suwartono, 2014) skala likert adalah suatu alat yang di gunakan untuk mengukur sikap dan pendapat seseorang atau sekelompok orang tentang fenomena sosial. Dalam penelitian ini digunakan skala likert lima poin, yaitu (1) sangat tidak baik, (2) tidak baik, (3) cukup, (4) baik, dan (5) sangat baik.

Tabel 1. Tabel Rekap Nilai Usability Testing

\begin{tabular}{|c|c|c|c|}
\hline No & Daftar Pertanyaan & \multicolumn{2}{|c|}{ Rata2 Nilai } \\
\hline \multicolumn{4}{|c|}{ Learnability } \\
\hline 1. & Kejelasan teks yang digunakan & 4,00 & \multirow{2}{*}{4,00} \\
\hline 2. & Kesesuaian menu yang ditampilkan & 4,00 & \\
\hline \multicolumn{4}{|c|}{ Efficiency } \\
\hline 3. & Kecepatan proses menampilkan isi content & 4,00 & \multirow{2}{*}{3,25} \\
\hline 4. & Kecepatan proses pengelolaan data & 3,5 & \\
\hline \multicolumn{4}{|c|}{ Memorability } \\
\hline 5. & Hasil yang diberikan jelas dan dapat dipahami & 3,00 & \multirow[b]{2}{*}{3,5} \\
\hline & Kemudahan dalam memahami isi dan proses sistem & 4,00 & \\
\hline \multicolumn{4}{|c|}{ Errors } \\
\hline 7. & Link menu dan proses yang eror & 3,5 & 3,5 \\
\hline \multicolumn{4}{|c|}{ Satisfaction } \\
\hline 8. & Tampilan Yang Menarik & 3,00 & 3,00 \\
\hline
\end{tabular}

Hasil penilaian dari responde dengan menggunakan metode usability testing, yaitu :

Learnability: Dalam aspek learnability dengan nilai dari tiga pertanyaan yang diajukan, memiliki rata - rata 4,00. Maka dapat disimpulkan bahwa sistem mudah dalam menggunakannya.

Efficiency: Dalam aspek efficiency dengan nilai dari dua pertanyaan yang diajukan, memiliki rata - rata 3,25. Maka dapat disimpulkan bahwa menu dan fungsi yang ada pada sistem sederhana atau tidak ribet.

Memorability: Dalam aspek memorability dengan nilai dari dua pertanyaan yang diajukan, memiliki rata - rata 3,5. Maka dapat disimpulkan bahwa menu dan fungsi yang ada sistem mudah di ingat oleh pengguna.

Errors: Dalam aspek errors dengan nilai dari satu pertanyaan yang diajukan, memiliki rata rata 3,5. Maka dapat disimpulkan bahwa sistem pakar diagnosis penyakit ayam beroiler yang telah dibuat sedikit terjadi kesalahan atau errors menu an fungsinya.

Satisfaction: Dalam aspek satisfaction dengan nilai dari satu pertanyaan yang diajukan, memiliki rata - rata 3,00. Maka dapat disimpulkan bahwa pengguna merasa puas dengan adanya sistem

Cara mengoperasikan Perangkat Lunak Bantu Pendaftaran Peserta Ujian (DPU) Pada Sekolah

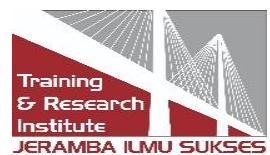


Dasar (SD) Di Dinas Pendidikan Dan Kebudayaan Kota Pagar Alam yaitu:

1. Buka File Browser atau Opera atau yang lain.

2. localhost/dinas_pendidikan

3. Maka akan tampil halaman utama perangkat lunak bantu pendaftaran peserta ujian (dpu) pada sekolah dasar (sd) di dinas pendidikan dan kebudayaan kota Pagar Alam

4. Komputer atau laptop yang diperlukan untuk mengakses web yaitu komputer atau laptop yang mempunyai akses ke internet dan mempunyai aplikasi browser. Kemudian untuk mengakses di localhost yaitu komputer atau laptop yang mempunyai aplikasi XAMPP dan browser.

Penjelasan tentang sistem adalah sebagai berikut:

\section{Desain Halaman Login}

Halaman ini dirancang untuk Pengguna Sistem agar dapat melakukan aktivitasnya dalam perangkat lunak bantu Pendaftaran Peserta Ujian (DPU) ini. Pada halaman ini pengguna harus memasukkan username dan password yang valid agar dapat melakukan aktivitasnya. Berikut gambaran nya.

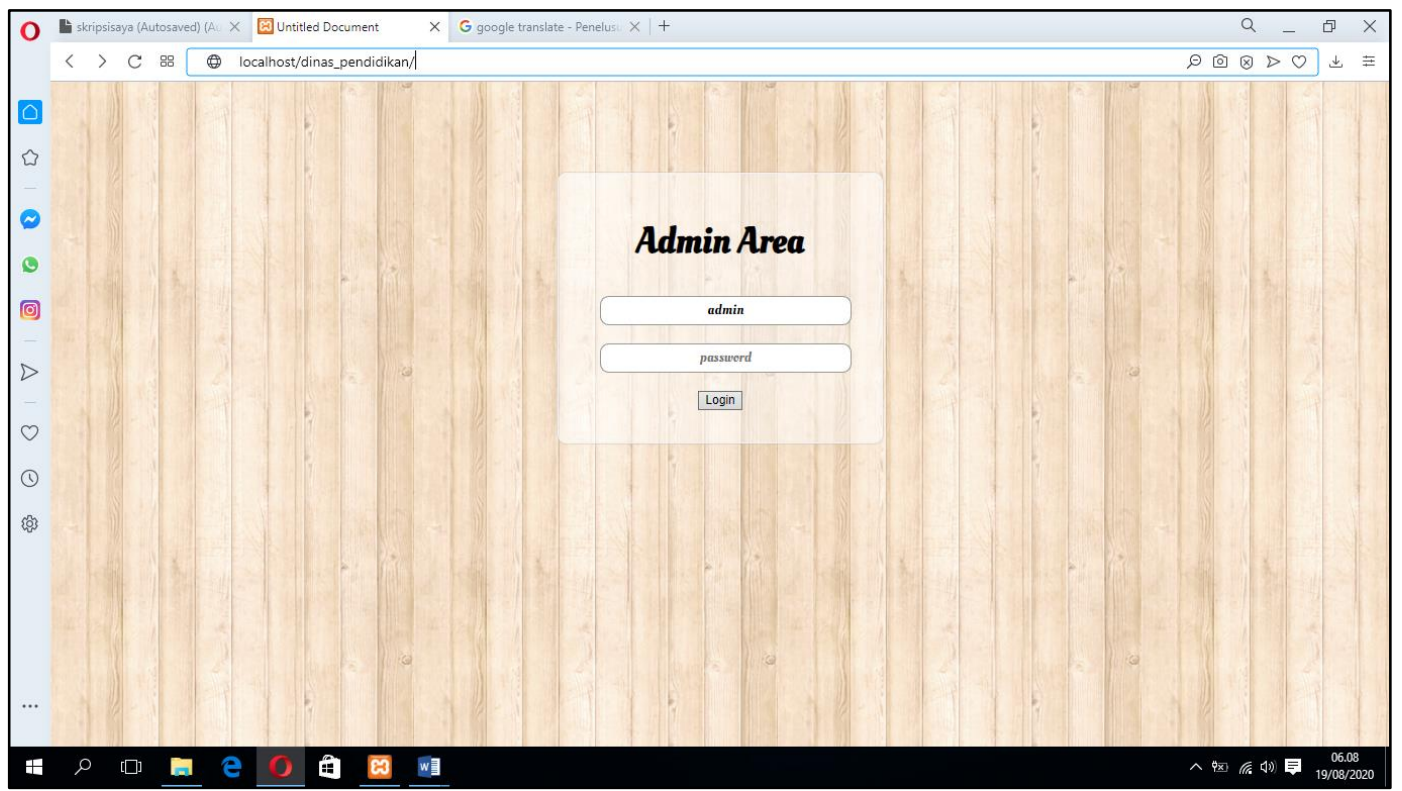

Gambar 4 Desain Halaman Login

Desain Halaman Utama

Setelah Operator Diknas memasukkan username dan password yang valid maka Operator diknas akan masuk ke halaman Utama. Halaman ini dirancang agar Operator diknas dapat melakukan proses kelola data pada

perangkat lunak bantu pendaftaran peserta ujian (DPU). Berikut adalah gambar. 


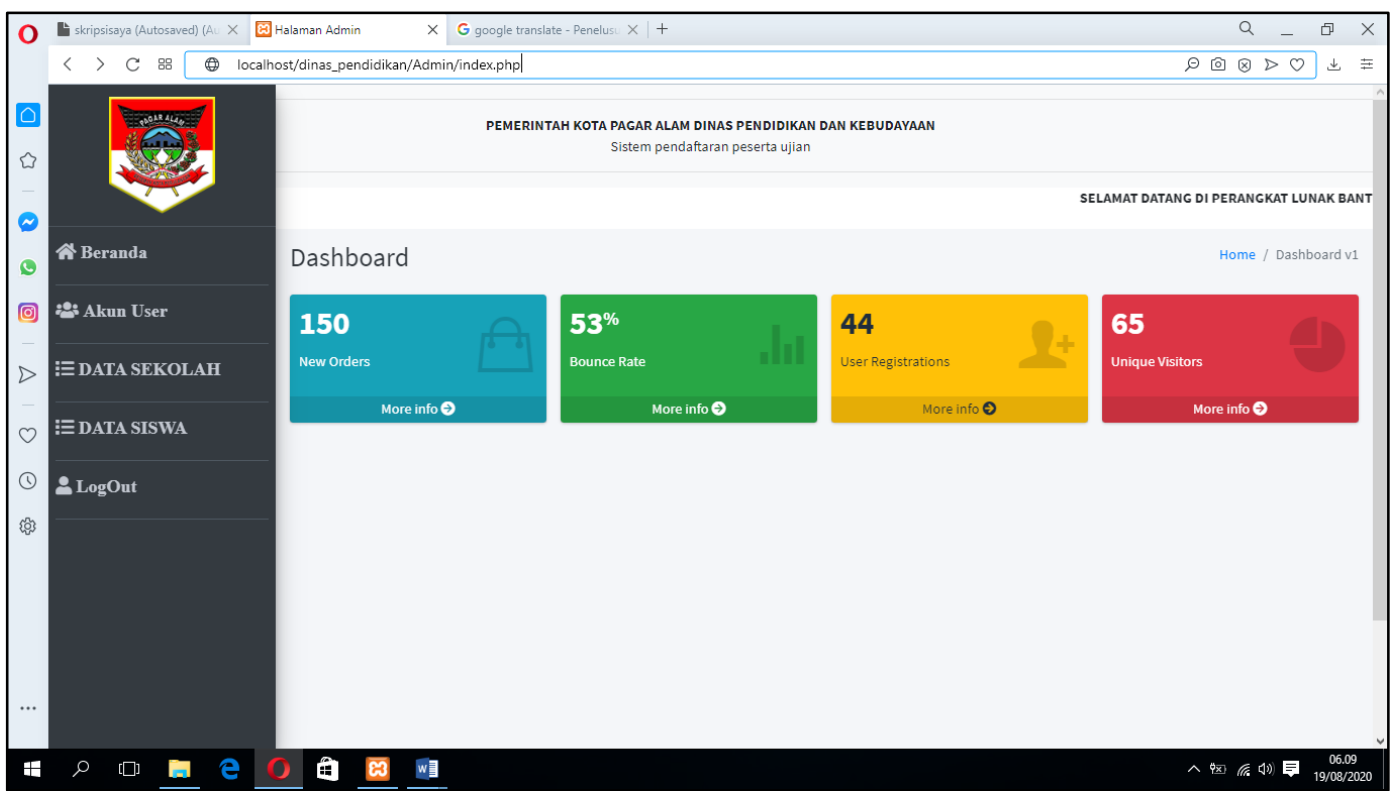

Gambar 5. Desain Halaman Utama

Desain Kelola Data Siswa

Halaman ini dirancang agar user dapat melakukan proses kelola data Siswa. Berikut rancangan data Siswa.

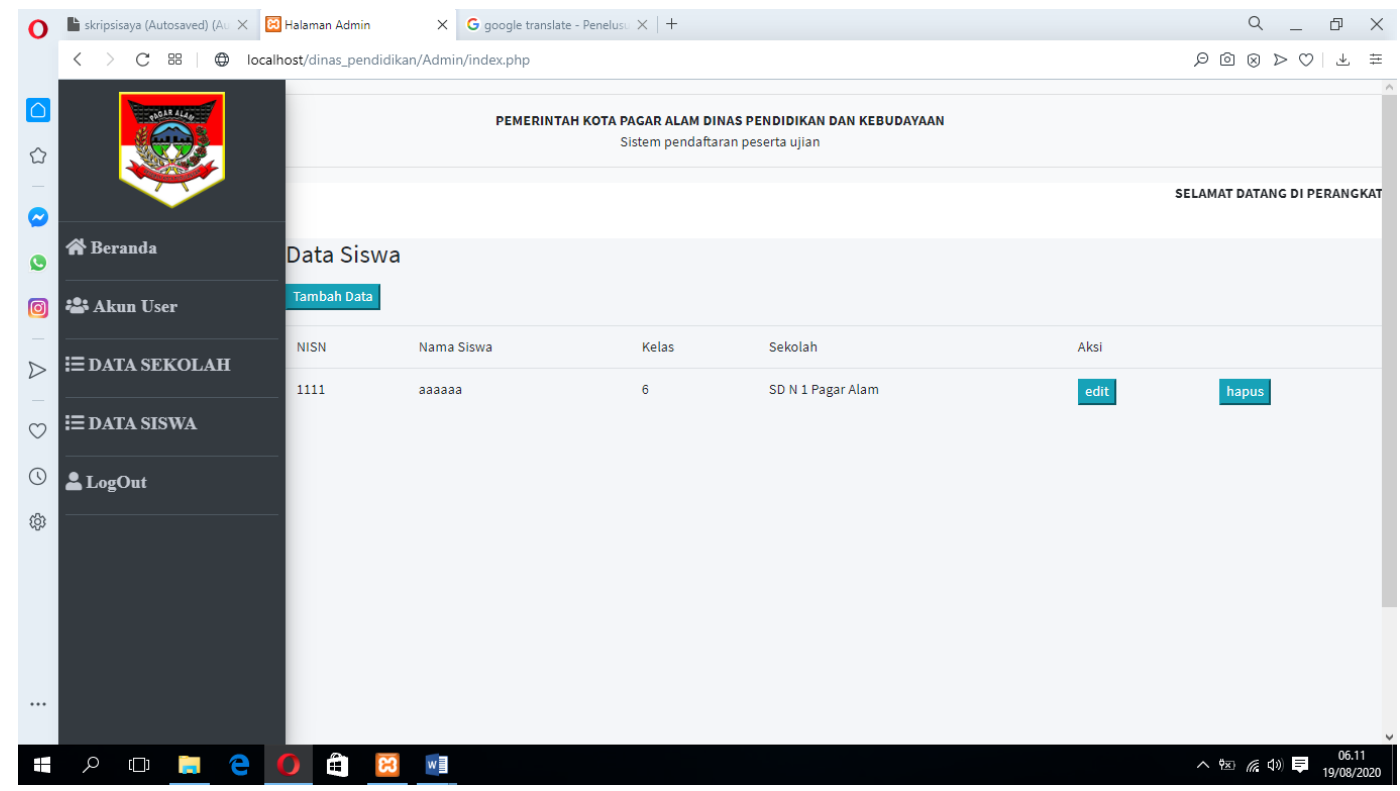

Gambar 6. Desain Kelola Data Siswa

Desain Input Data Siswa

Halaman ini berfungsi untuk menambahkan data siswa pada perangkat lunak bantu pendaftaran peserta ujian. Berikut rancangan input data siswa.

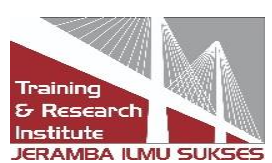




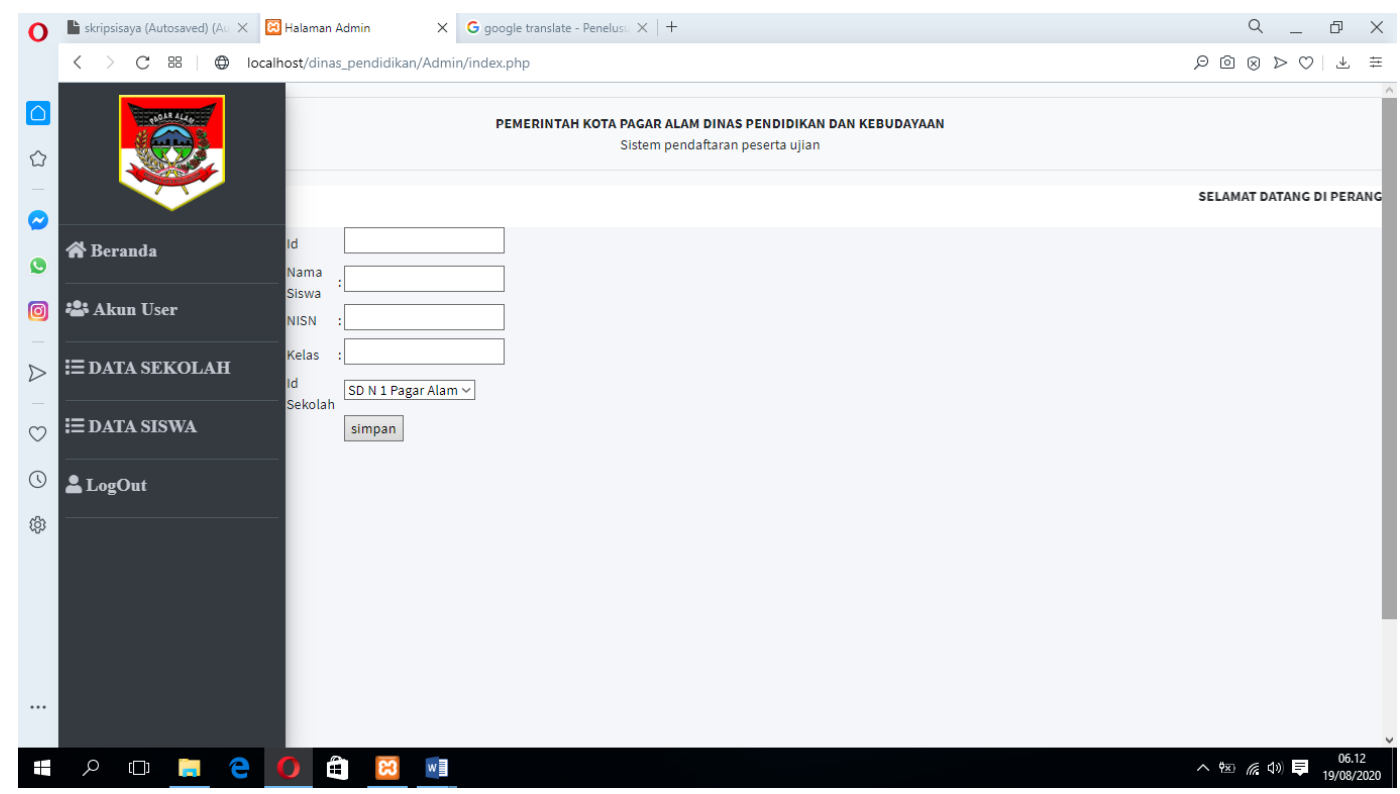

Gambar 7 Desain Input Data Siswa

Desain Output Kartu Ujian

Ini adalah desain output Kartu Ujian pada sekolah dasar (SD) di Dinas Pendidikan Dan Kebudayaan Kota Pagar Alam. Berikut rancangan output Kartu Ujian.

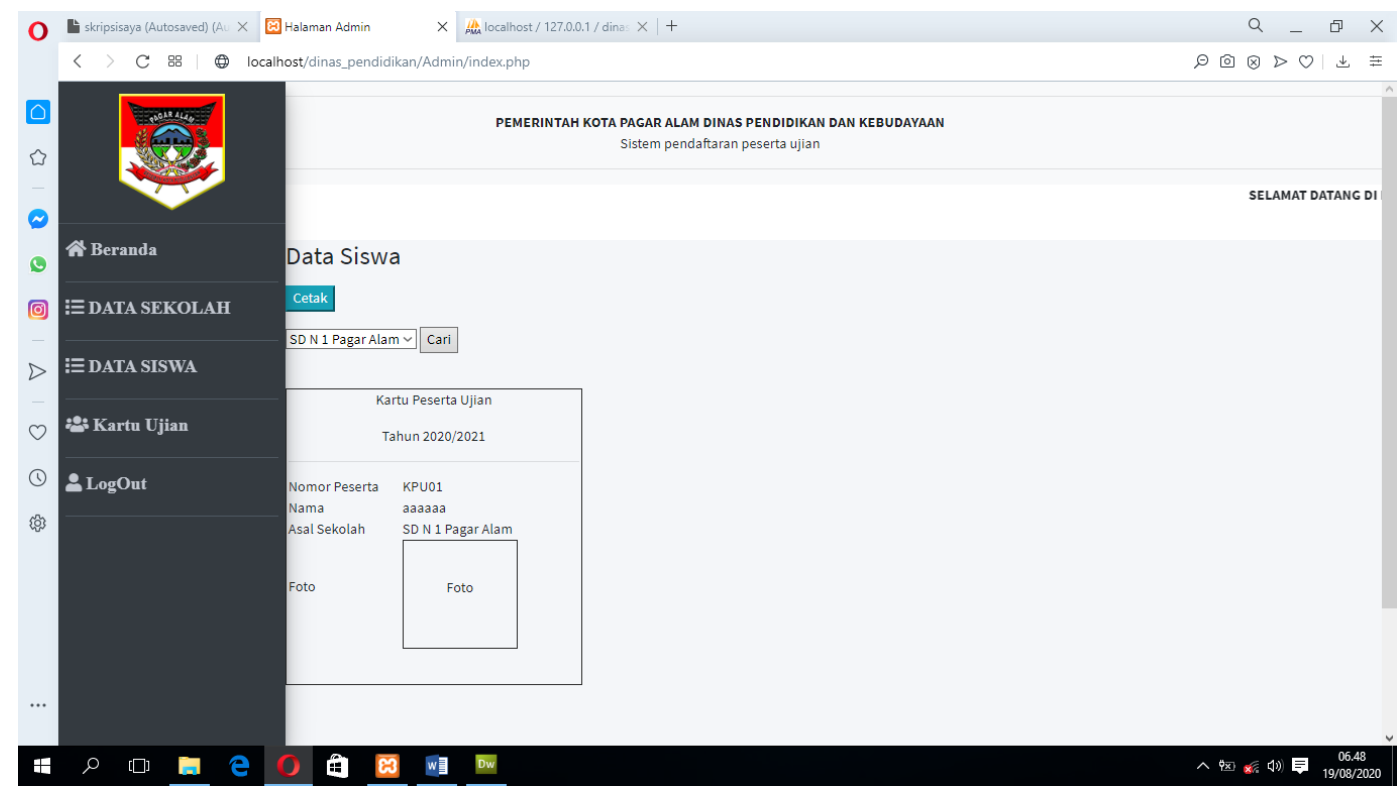

Gambar 8. Desain Output Kartu Ujian

Desain Rekapulasi Peserta Ujian

Gambar dibawah ini adalah rancangan rekapulasi data siswa pada perangkat lunak bantu pendaftaran peserta ujian (DPU) pada sekolah dasar (SD) di Dinas Pendidikan Dan Kebudayaan Kota Pagar Alam.

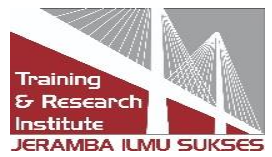




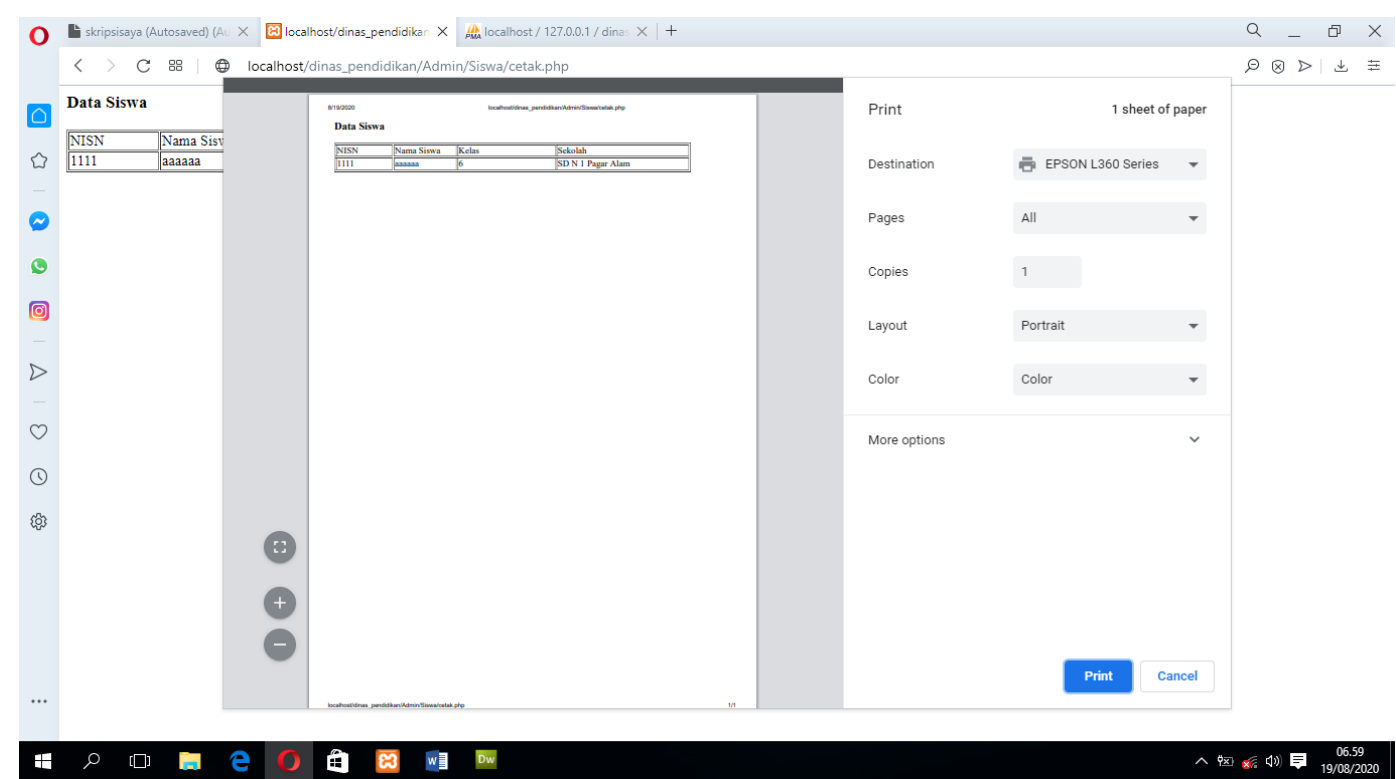

Gambar 9 Rekap data Peserta

\section{Kesimpulan}

Perangkat Lunak Bantu Pendaftaran Peserta Ujian (DPU) Pada Sekolah Dasar (SD) Di Dinas Pendidikan Dan Kebudayaan Kota Pagar Alam dapat dibuat dengan menggunakan pemrograman PHP dan database MySql. Perangkat lunak bantu ini dapat membantu dinas pendidikan dan kebudayaan dalam merekap data tentang daftar peserta ujian (DPU). Admin dapat mencetak laporan data siswa dari masing-masing sekolah. Setiap sekolah dasar yang sudah di daftarkan oleh Admin dapat melakukan input atau registrasi siswa yang akan mengikuti ujian. Setiap sekolah dasar dapat melakukan cetak kartu pelajar untuk masingmasing siswa.

\section{Referensi}

A.S, R., \& Shalahuddin, M. (2013). Analisis dan Desain Sistem Informasi, Bandung: Informatika

A.S, R., \& Shalahuddin, M. (2013). Pemodelan Visual dengan UML, Bandung: Informatika.

A.S, R., \& Shalahuddin, M. (2013). Rekayasa Perangkat Lunak Tersruktur dan Berorientasi Objek. Bandung: Informatika.

Anggiani Septima, Eko Retnanadi (2012). Perancangan informasi subsistem guru di sekolah pesantren persatuan islam 99 ranca bango,ISSN :2302-7339 Vol.09 No.40 2012.http:// jurnal.sttgarut.ac.id

Antoni, D., \& Akbar, M. (2019). E-supply chain management value concept for the palm oil industry. Jurnal Sistem Informasi, 15(2), 15-29.

Antoni, D., Fikari, D., \& Akbar, M. (2018). The readiness of palm oil industry in enterprise resource planning. Telkomnika, 16(6), 2692-2702.

Antoni, D., Jie, F., \& Abareshi, A. (2020). Critical factors in information technology capability for enhancing firm's environmental performance: case of Indonesian ICT sector. International

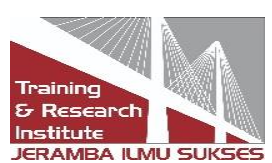


Journal of Agile Systems and Management, 13(2), 159-181.

Cucu Suhendar (2015).Rancang Bangun Sistem Informasi Penerimaan Siswa Baru Pada Smk Ciledug Al-Musaddadiyah Garut,ISSN :2302-7339 Vol.1 No.12 2015.http:// jurnal.sttgarut.ac.id

Fauzi, F., Dencik, A. B., \& Asiati, D. I. (2019). Metodologi Penelitian untuk manajemen dan akuntansi. Jakarta: Salemba Empat.

Imam Suja. (2005). belajar database mengunakan mysql. yogyakarta : cv andi offset.

M.Rifki Tsani,Nurhadianto (2015).Sistem Informasi Ujian pada smk bina islam mandiri kersana berebes tegal,e-ISSN :2477-8079 Cogito Smart Journal/ Vol.1 No.1/Desember 2015.

M.Rizki Alpandi (2016).sistem informasi akademik di smp negeri 2 kecamatan gaung anak serka,E-ISSN :2540-9717,ISSN :2302-8149 Vol.5 No.3,September 2016:8-13.

Sezi Zalina, Azis Ahmadi (2015). Perancangan Tes Masuk pada Sekolah Menengah Kejuruan (SMK) Negeri 3 Pacitan, ijns - indonesian journal on networking and security - volume 4 No 2 - April 2015 - ijns. Apmmi org.

Sibero . (2013). 1 menit belajar bikin php dengan php \& query. yogyakarta: mediakom.

\section{Copyrights}

Copyright for this article is retained by the author(s), with first publication rights granted to the journal.

This is an open-access article distributed under the terms and conditions of the Creative Commons Attribution license (http://creativecommons.org/licenses/by/4.0/) 